\title{
Influence of Construction of High-rise Building on Surrounding Environment and Neighboring Buildings
}

\author{
Songan Liu ${ }^{1,} \mathrm{a}^{*}$ and Yafei Liu ${ }^{1}$ \\ ${ }^{1}$ School of Resource Exploration \& Civil Engineering, The Engineering \& Technology College of \\ Chengdu University of Technology, Leshan, Sichuan 614000, China \\ alsa_lyf@sina.com \\ * The corresponding author
}

Keywords: High-rise building; Surrounding environment; Neighboring building

\begin{abstract}
High-rise buildings are currently widely implemented, deep foundation pit engineering as a high-rise building construction process the most dangerous part of a more prominent highlights of its importance. Deep foundation pit engineering has the characteristics of high risk, long construction period and difficult construction, and the deep foundation pit accident is caused by the damage of the supporting structure. As the deep foundation pit engineering is in the basic construction stage, and for the foundation of the construction of deep foundation pit support structure of the study is not common. Therefore, this paper studies and analyzes this problem on the basis of understanding some basic theories of deep foundation pit engineering. According to the construction of high-rise buildings for the impact of the surrounding environment, statistical data, the proportion of the two high is the construction of the pile construction and foundation pit construction. The article has studied and discussed these two aspects of influencing factors, and put forward some effective preventive measures in practical operation.
\end{abstract}

\section{Introduction}

At present, China's construction market with the economic take-off and the formation of a large-scale, complex and complex system of diversification. Large and medium-sized cities across the country, high-rise and high-rise buildings have become a city image, the overall strength of the economy and the people's living standards. In the process of design and construction of high-rise and super-high-rise buildings, the deep foundation pit support structure has become the focus of the research as a technical difficulty, many security risks and a serious economic loss of accidents[1]. At present, China's construction market with the economic take-off and the formation of a large-scale, complex and complex system of diversification. Large and medium-sized cities across the country, high-rise buildings have become a city image, the overall strength of the economy and the people's living standards. In the process of design and construction of high-rise and super-high-rise buildings, the deep foundation pit support structure has become the focus of the research as a technical difficulty, many security risks and a serious economic loss of accidents[2].

At present both at home and abroad on the deep foundation pit support structure research has reached a more advanced level. In the design of supporting structure: the main design research methods are limit equilibrium theory, elastic resistance method, finite element method and so on[3]. In recent years, with the development of science and technology and the emergence of some new research methods, support design theory from the initial strength control and stability analysis of the rough design to the deformation control design proposed in recent years[4]. If the deformation of the foundation pit to meet the requirements, then the strength and stability will naturally meet, in turn, if the strength and stability to meet the requirements, the deformation limit may not be able to achieve, therefore, deformation control is both a design purpose and design method[5]. In the form of support structure is also diversified, the traditional pile, wall, support, anchor, pull and so are passive support form, that is, by passive resistance to the force of the soil and with the balance to achieve the purpose of support, now 
the trend is from the economic and security point of view, from improving the performance of soil to start, as far as possible to maximize the mobilization of soil strength.

\section{The Impact of the Construction of the Pile Foundation on the Surrounding Environment}

In the construction of the building, the higher the building, the requirements for the foundation of the building will be more high, the most basic to bear the load for this high-rise buildings[6]. When the building is built in a more intensive place, this time the basic form of the building must use the pile foundation and other forms of composite foundation. These types of construction methods are often due to the complexity of the construction method, in the construction of the squeeze effect and other aspects of the vibration generated by a variety of factors, the impact on the surrounding environment is more serious (Fig. 1).

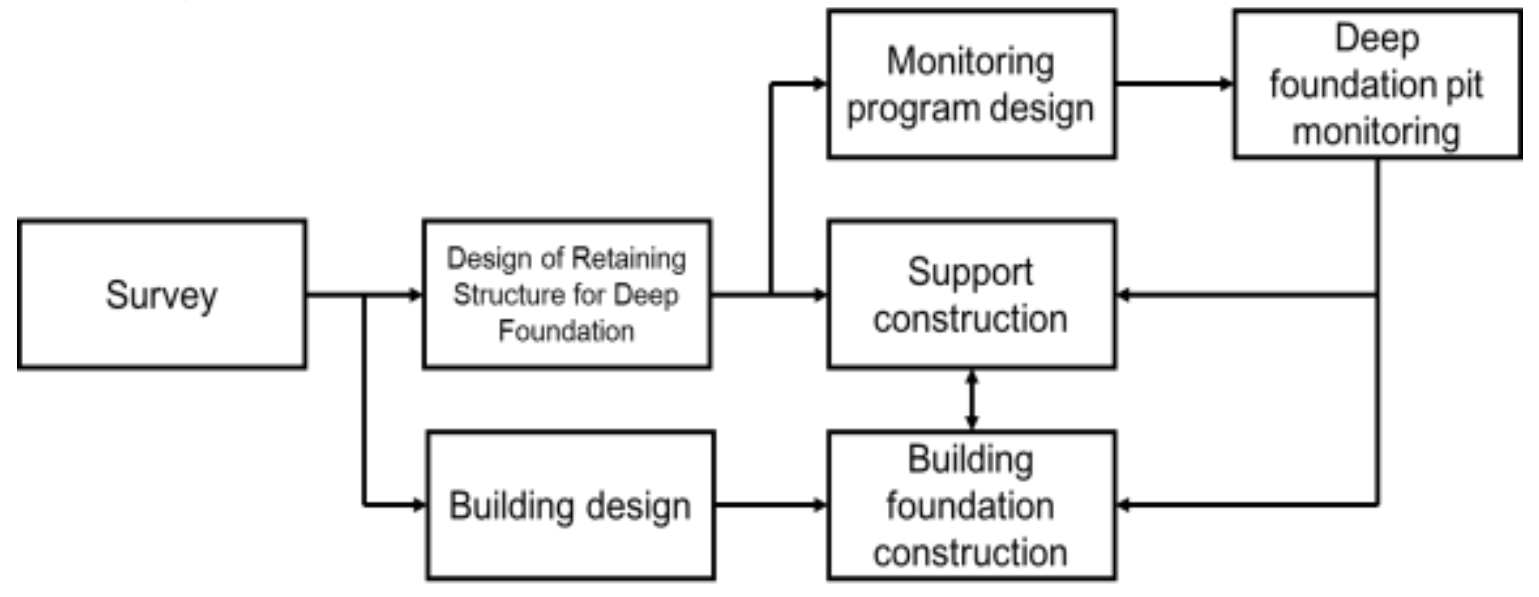

Figure 1. Deep foundation pit engineering process

Deep foundation pit in the relevant specification is to carry out the underground part of the building construction and underground facilities, equipment, buried from the ground began to dig down, the depth of $5 \mathrm{~m}$ or more space. Deep foundation pit has the following characteristics:

Environmental effects: excavation of deep foundation pit works will cause the change of groundwater level and stress field in the surrounding ground, resulting in the deformation of the surrounding soil, adversely affect the adjacent buildings, structures and municipal underground pipe network. The impact will seriously endanger the adjacent buildings, structures and municipal underground pipe network safety and normal use. At the same time a large number of earth transport also have an impact on traffic.

Large amount of work, tight schedule: As the deep excavation depth is generally large, only the earth excavation is generally tens of thousands to hundreds of thousands of cubic meters. It is not only the requirements of construction management, but also it is of great significance to reduce the deformation of foundation retaining structure and reduce the deformation of surrounding environment[7].

High quality requirements: the excavation of the deep excavation area is the future of the underground structure of the construction area, and sometimes even deep foundation pit support structure or part of the permanent structure of the underground, and the quality of the underground structure will directly affect the quality of the upper structure. Therefore, we must ensure the quality of deep foundation pit engineering in order to ensure the underground structure and the structure of the superstructure of the project quality, and thus ensure the quality of the entire building works.

\section{Impact of Foundation Pit Construction on the Surrounding Environment}

The impact of the construction of the pit on the surrounding environment is also a multifaceted, such as the impact of the construction of the support structure on the surrounding environment, the reduction of the groundwater level and the excavation of the foundation pit. 
Support the Impact of the Pile on the Surrounding Environment During Construction. In order to make the foundation pit in the process of excavation can be very stable, support the structure will generally use the row of pile support works which contains the pile, prefabricated pile, sheet pile and other types. Most of these types are crowded soils, so in the construction of the time in order to reduce the impact of the surrounding environment should pay attention to the sand, soft soil or groundwater level piling, if the use of artificial piling, Often due to improper excavation holes caused by sand or collapse and other serious problems arise, so in a building-intensive place is not able to use this type of piling method. In some of the construction process, for some reason, the construction workers used the method of artificial piling, but did not use to take effective protection measures, resulting in the emergence of quicksand, piping and other phenomena, resulting in the surrounding area of land appeared a wide range of collapse, To the nearby buildings brought a very big damage (Table 1).

Table 1 Support structure damage mechanism classification.

\begin{tabular}{|c|c|c|}
\hline \multicolumn{2}{|r|}{ The way of destruction } & Destruction mechanism \\
\hline \multirow{2}{*}{$\begin{array}{l}\text { The surrounding } \\
\text { environment is } \\
\text { damaged }\end{array}$} & Buildings, structures, cracks and so on & Soil subsidence \\
\hline & Underground pipeline damage & Soil subsidence \\
\hline \multirow{9}{*}{$\begin{array}{l}\text { Support system } \\
\text { damage }\end{array}$} & Foundation Pit Support Leakage & Enclosure instability \\
\hline & Support structure as a whole instability & Enclosure instability \\
\hline & Failure of foundation pit system & $\begin{array}{l}\text { The instability of the support } \\
\text { structure causes the structural failure } \\
\text { of the envelope }\end{array}$ \\
\hline & Enclosure damage & Enclosure instability \\
\hline & Submission of damage & Enclosure damage \\
\hline & Pit landslide & Support structure damage \\
\hline & Soil uplift and destruction & Support system instability \\
\hline & Dumping & $\begin{array}{l}\text { The instability of the support } \\
\text { structure causes the structural failure } \\
\text { of the envelope }\end{array}$ \\
\hline & Pit bottom pipe surge sand & $\begin{array}{c}\text { Support system damage or } \\
\text { instability }\end{array}$ \\
\hline
\end{tabular}

Impact of Foundation Pitfall on the Surrounding Environment. Foundation excavation in the process of excavation will basically require manual operation to reduce groundwater. Once the groundwater is drained, the ground will sink, so that it will have a great impact on the surrounding geological environment, and will also seriously affect the social environment. The artificial precipitation of the foundation pit project will lead to the decline of the groundwater in the project, which will cause the soil to be consolidated. The ground will appear to settle down, and the surrounding buildings will settle in different degrees. This is a serious consequence of the major defects that occur when the groundwater treatment is improper 
Other Effects. In addition to the above-mentioned factors affecting the environment, there are other aspects of the impact of the construction of the support structure. For example, soil anchor construction in the actual construction process may occupy the planning of red lines other than the underground space, will affect the construction of the normal construction of the operation.

\section{Summary}

In order to protect the neighboring buildings from the preventive measures, as far as possible to reduce the impact on the surrounding buildings and the environment, the construction of the pit in the construction process to do the following points on the surrounding buildings underground pipe network foundation Situation, type, etc., and an accurate analysis of the allowable value of its deformation is based on the allowable values of the accurate data analyzed for the surrounding buildings and the underground pipe network. And puts forward a reasonable and effective supporting system for foundation pit engineering, and makes a correct assessment of the surface subsidence caused by excavation of foundation pit. For the support system can meet the safety of the surrounding buildings to make accurate judgments of the foundation pit earthwork in the process of excavation caused by the deformation of the support structure and groundwater level reduction caused by ground settlement, is the foundation pit engineering The most important reason for the impact on the surrounding buildings and municipal pipelines. The impact of the foundation works on the surrounding environment is unavoidable, but it is necessary to take mitigation measures as much as possible during the construction process. Maintain the safety of municipal pipelines and the surrounding construction network.

\section{References}

[1] Toja-Silva F, Lopez-Garcia O, Peralta C, et al. An empirical-heuristic optimization of the building-roof geometry for urban wind energy exploitation on high-rise buildings[J]. Applied Energy, 2016, 164: 769-794.

[2] Barbosa S, Ip K. Perspectives of double skin façades for naturally ventilated buildings: A review[J]. Renewable and Sustainable Energy Reviews, 2014, 40: 1019-1029. Pisello A L, Castaldo V L, Poli $\mathrm{T}$, et al. Simulating the thermal-energy performance of buildings at the urban scale: evaluation of inter-building effects in different urban configurations[J]. Journal of Urban Technology, 2014, 21(1): 3-20.

[3] Dongmei H, Ledong Z, Quanshun D, et al. Aeroelastic and aerodynamic interference effects on a high-rise building[J]. Journal of Fluids and Structures, 2017, 69: 355-381.

[4] Wong I, Baldwin A N. Investigating the potential of applying vertical green walls to high-rise residential buildings for energy-saving in sub-tropical region[J]. Building and Environment, 2016, 97: 34-39.

[5] Salata F, Golasi I, de Lieto Vollaro A, et al. How high albedo and traditional buildings' materials and vegetation affect the quality of urban microclimate. A case study[J]. Energy and Buildings, 2015, 99: 32-49.

[6] Liu J, Heidarinejad M, Gracik S, et al. The impact of exterior surface convective heat transfer coefficients on the building energy consumption in urban neighborhoods with different plan area densities[J]. Energy and Buildings, 2015, 86: 449-463.

[7] Chan A L S. Investigation on the appropriate floor level of residential building for installing balcony, from a view point of energy and environmental performance. A case study in subtropical Hong Kong[J]. Energy, 2015, 85: 620-634. 